\title{
Pemberdayakan Kompetensi Guru dalam Penguatan Model Pembelajaran Cooperative Learning Siswa di SDN Kenari 07 Pagi
}

\author{
Alberth Supriyanto Manurung ${ }^{1}$, Abdul Halim ${ }^{2}$, Ainur Rosyid ${ }^{3}$ \\ 1,2,3Pendidikan Guru Sekolah Dasar, FKIP, Universitas Esa Unggul, Jakarta, Indonesia \\ Email: ${ }^{1}$ alberth@esaunggul.ac.id, ${ }^{2}$ abdul.halim@esaunggul.ac.id, ${ }^{3}$ ainur.rosyid@esaunggul.ac.id
}

\begin{abstract}
Cooperative Learning is a model of logic regarding the form, arrangement, magnitude and concepts related to each other. The concept is always related to everyday human life. Cooperative Learning in the form of Empowering Teacher Competencies in Strengthening Cooperative Learning Models Students not only increase curiosity but always develop according to the times, Cooperative Learning is a model that aims to instill and develop the learning process in teachers. Based on the results of observations at SDN Kenari 07 Pagi in the learning process, teachers still use conventional or teacher-centered teaching methods as information providers, with the literacy movement students are expected to improve the good quality of each problem-solving concept in the form of application questions. The purpose of this community service activity for PKM is Empowering Teacher Competence in Strengthening Cooperative Learning Learning Models is to increase knowledge which changes from time to time. The subjects of this community service are all students at SDN Kenari 07 Pagi.
\end{abstract}

Keywords: Empowerment, Teacher Competence, Cooperative Learning

\begin{abstract}
Abstrak
Pembelajaran Cooperative Learning adalah Model tentang logika mengenai bentuk, susunan, besaran dan konsep berhubungan satu sama lain. Dalam konsepnya selalu berhubungan dengan kehidupan manusia sehari-hari. Pembelajaran Cooperative Learning dalam bentuk Pemberdayakan Kompetensi Guru Dalam Penguatan Model Pembelajaran Cooperative Learning Siswa bukan hanya sekedar meningkat rasa ingin tahu tapi selalu berkembang sesuai perkembangan zaman, Pembelajaran Cooperative Learning adalah model yang bertujuan untuk menanamkan dan mengembangkan proses pembelajaran pada guru. Berdasarkan hasil observasi di SDN Kenari 07 Pagi pada proses pembelajaran guru masih menggunakan cara mengajar yang konvensional atau berpusat pada guru sebagai pemberi informasi, dengan adanya gerakan literasi siswa diharapkan meningkatkan kualitas yang baik dari setiap konsep pengerjaan masalah dalam bentuk aplikasi soal. Tujuan kegiatan pengabdian kepada masyarakat ini untuk PKM Pemberdayakan Kompetensi Guru Dalam Penguatan Model Pembelajaran Cooperative Learning adalah untuk menambah ilmu pngetahuan yang tiap waktu mengalami perubahan. Subjek pengabdian kepada masyarakat ini adalah seluruh siswa di SDN Kenari 07 Pagi.
\end{abstract}

Kata Kunci: Pemberdayakan, Kompetensi Guru, Pembelajaran Cooperative Learning

\section{A. PENDAHULUAN}

SDN Kenari 07 Pagi merupakan sekolah negeri dengan kepemilikan Pemerintah Pusat dan berada dalam pembinaan Suku Dinas Pendidikan Wilayah Jakarta Pusat. Berdiri dengan SK Pendirian tertanggal 1981-08-19, SK Izin Operasional tertanggal 1910-01-01 dan Nomor Pokok Statistik Nasional (NPSN) 20100539. Gedung sekolah berdiri di atas lahan milik sendiri seluas $4488 \mathrm{~m}^{2}$ dan status akreditasi sekolah B.

Sekolah ini mempunya visi terwujudnya peserta didik yang cerdas, terampil, berbudi pekerti luhur berdasarkan iman dan takwa. Sementara beberapa misinya antara lain, 1) melaksanakan pembelajaran dan bimbingan secara efektif sehingga setiap siswa 
berkembang secara optimal dengan potensi yang dimiliki, 2) mendorong dan membantu setiap siswa untuk mengenal potensi diri, 3) menumbuhkan semangat belajar secara intensif kepada seluruh peserta didik, 4) menumbuhkan penghayatan dan pengamalan terhadap ajaran agama dan budaya bangsa.
Lokasi sekolah berada di Jalan Salemba Raya IV, RT. 03, RW. 06, Kelurahan Kenari, Kecamatan Senen, Jakarta Pusat. Peta (denah) lokasi sekolah dengan beberapa tempat penting di sekitarnya terlihat dalam gambar berikut

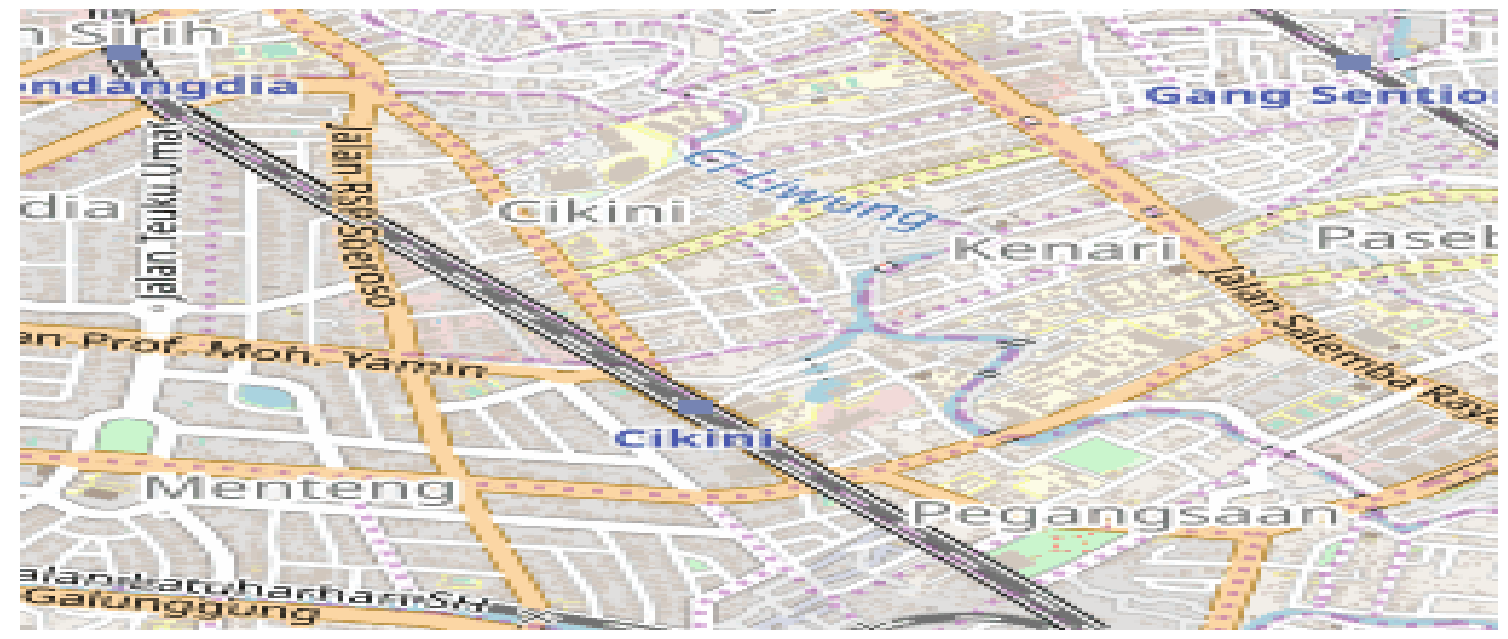

Gambar 1. Peta (denah) Lokasi SDN Kenari 07 Pagi

Dalam pengelolaannya, sekolah difasilitasi dengan kondisi standar dan mencakup ruang kelas (19), ruang kepala sekolah (1), ruang guru (1), ruang tata usaha (1), ruang UKS (1), ruang ibadah/mushola (1), perpustakaan (2), ruang literasi (1), laboratorium IPA (1), laboratorium agama (1), toilet siswa (24), toilet guru (12), kantin sekolah (5), gudang (2), aula sekolah (1), dan lapangan upacara (1). Kondisi fasilitas yang kurang baik berkaitan dengan instalasi air, jaringan internet, beberapa lantai kelas yang mulai rusak, dan beberapa lampu yang kurang terang cahayanya. Sementara itu, fasilitas laboratorium komputer dan laboratorium bahasa belum ada. Fasilitas internet tersedia sebatas ruang administrasi ketatausahaan.

Penyelenggaraan sekolah adalah 5 hari kerja dengan beberapa program pembiasaan yang dilakukan setiap harinya. Adapun program pembiasaan tersebut antara lain, Senin (upacara bendera), Selasa (senam bersama untuk siswa kelas 1-3), Rabu (doa bersama), Kamis (senam bersama untuk siswa kelas 4-6). Jam belajar untuk kelas 1 dan 2 hanya sampai pukul 10.45 WIB, sedangkan kelas 3-6 sampai pukul 12.10 WIB.

Sekolah ini dikelola oleh 22 guru yang terdiri dari 15 Guru Tetap/PNS, 0 guru bantu CPNS, 0 guru CPNS K2, 0 guru KKI -UMP K2, dan 7 guru KKIUMP. Sekolah ini juga diperbantukan oleh 4 tenaga tata usaha dan 3 penjaga sekolah. Data statistik lain menunjukkan pemenuhan rasio kelas : siswa adalah 1 : 32 yang dialokasikan dalam 16 rombongan belajar (rombel). Rombel tersebut terdiri atas pengelompokan 3 rombel kelas I (91 siswa), 3 rombel kelas II (93 siswa), 3 rombel kelas 3 (95 siswa), 2 rombel kelas IV (63 siswa), 3 rombel kelas V (94 siswa), dan 3 rombel kelas VI (78 siswa).

Sekolah Kenari 07 Pagi merupakan sekolah inklusi. Hampir tiap kelas memiliki siswa berkebutuhan khusus yang berkisar antara 2-4 siswa. Dalam hal pembelajaran di kelas, tentu guru memiliki perlakuan khusus yang disesuaikan dengan kemampuan siswa inklusi tersebut. Meski kebutuhan khusus yang dimiliki siswa berbedabeda, dominan dari mereka memiliki keterbatasan dalam hal menyerap pelajaran di kelas(Weeks, 2015). Namun dari sisi sosial, para siswa di sekolah ini mampu untuk berbaur satu sama lain dan saling menghormati. Jika dilihat berdasarkan latar belakang ekonomi, kebanyakan siswa berasal dari keluarga berlatar ekonomi menengah ke bawah. Berikut merupakan beberapa gambaran mengenai kondisi dan situasi di SDN Kenari 07 Pagi.

Dalam kaitannya dengan pengembangan Pembelajaran Cooperative Learning, berdasarkan hasil wawancara dengan kepala sekolah, guru, beberapa siswa, dan observasi peneliti, ditemukan beberapa permasalahan yang dihadapi sekolah ini. Permasalahan tersebut berkaitan dengan kurangnya kemampuan siswa untuk memahami isi teks(Wanelly \& Fauzan, 2020) bahasa Indonesia yang terdapat dalam buku pelajaran, kurangnya pemahaman siswa untuk memaknai berbagai istilah, keterbatasan lambang yang dimiliki siswa ketika menjelaskan suatu konsep atau makna dari suatu bacaan, media literasi yang digunakan guru kurang membangkitkan motivasi siswa untuk 
membaca, serta kurangnya rasa percaya diri siswa ketika menjelaskan isi teks yang sudah dibacanya.

Atas dasar itulah program pengembangan Pembelajaran Cooperative Learning menjadi penting untuk dilakukan. Meski beberapa permasalahan dominan berasal dari siswa, instruktur melihat bahwa peran guru juga penting. Agar siswa termotivasi untuk memaksimalkan kemampuan berpikir kreatif dan mengembangkan Pembelajaran Cooperative Learning, guru perlu memiliki bekal yang lebih banyak lagi sebelum mengajarkan materi-materi matematika di kelas(Nurlaila, 2019). Salah satu upaya yang perlu dilakukan adalah dengan menerapkan beberapa permainan tradisional sebagai media pengembangan Pembelajaran Cooperative Learning di kelas(Manurung. S. Alberth, halim. A, 2020). Media tersebut diharapkan dapat mendorong Pembelajaran Cooperative Learning siswa untuk memperkaya kemampuan Cooperative Learning di SDN Kenari 07 Pagi.

\section{B. PELAKSAAAN DAN METODE}

Mengacu pada analisis situasi dimuka, untuk melaksanakan pengembangan Pembelajaran Cooperative Learning bagi siswa, dapat diidentifikasi berbagai masalah yang sangat berpengaruh signifikan terhadap isu masalah berikut ini(Slameto, 2010). Mitra yang akan dilibatkan dalam kegiatan ini adalah SDN Kenari 07 Pagi. Sekolah tersebut berada di Kelurahan Kenari, Kecamatan Senen Kota Jakarta Pusat. Jarak lokasi mitra dari Universitas Esa Unggul lebih kurang 15 $\mathrm{km}$. Berdasarkan informasi yang didapat dari kepala sekolah dan guru kelas di SDN Kenari 07 Pagi, hampir $70 \%$ siswa kelas tinggi terutama yang perempuan memiliki kemampuan berpikir yang rendah untuk meningkatkan prestasi. Secara keseluruhan jumlah siswa laki-laki adalah 249 orang dan siswa perempuan ada 265 siswa yang dibantu oleh sebanyak 10 guru laki-laki dan 12 guru perempuan. Beberapa guru pernah mendapat kesempatan untuk mengikuti kegiatan-kegiatan peningkatan kualitas pembelajaran. Namun, sosialisasi dan aplikasi pengetahuan yang diperoleh kurang maksimal dilakukan. Bahkan beberapa sumbangan baik media maupun buku jarang digunakan dalam proses pembelajaran di sekolah dengan alasan kurangnya pendampingan(Randeska Manullang, 2017).

Sebenarnya dalam pembelajaran perlu dilakukan inovasi untuk meningkatkan hasil belajar sehingga dapat menumbuhkan sikap positif anak dalam belajar. Perlu juga dilakukan kegiatan-kegiatan yang dapat meningkatkan pemahaman dan keterampilan guru dalam melakukan inovasi pembelajaran. Sebagai bagian dari perguruan tinggi yang menghasilkan guru, maka perlu untuk lebih pro aktif melakukan kegiatan yang memberi manfaat positif bagi guru. Oleh karena itu perlu dilakukan program atau kegiatan membangun paradikma seorang guru(Zerri Rahman Hakim, Taufik,M.Pd, 2018).

Masalah spesifik yang benar-benar dihadapi kelompok usaha (mitra) dalam jangka pendek, antara lain:

a) Masalah variasi rumusan yang kurang banyak sehingga guru tidak mendapat penyelesaian dengan alternatif yang berbeda.

b) Minimnya pengetahuan tentang pengembangan Pembelajaran Cooperative Learning.

Untuk menyelesaikan permasalahan tersebut, maka pengusul mencoba membuat pelatihan cara memahami pengembangan Pembelajaran Cooperative Learning secara efektif dan berjenjang.Kegiatan Solusi yang ditawarkan melalui kegiatan ini adalah membimbing dan melatih siswasiswa siswa sekolah dasar memberikan pemberdayaan kompetensi guru dalam penguatan Pembelajaran Cooperative Learning yang baik saat awal pembelajaran maupun akhir pelajaran sehingga menumbuhkan sikap positif dari dalam diri siswa. Dampak yang diharapkan dari kegiatan ini adalah terbentuknya kebiasaan memberikan Penguatan Pembelajaran Cooperative Learning pada siswa di sekolah mitra, dengan cara membiasakan diri memberi cerita yang positif dengan mengambil contoh masyarakat yang berhasil pada bidang tertentu. Dimana setiap hari guru wajib memberikan inspirasi yang positif dalam mendampingi dan membimbing siswa sehingga muncul diskusi kecil diantara siswa kemudian tiap siswa menjelaskan makna motivasi yang diberikan guru tersebut(Nurlaila, 2019).

Sasaran dalam kegiatan ini adalah siswa-siswa sekolah dasar. Pertama sekali siswa-siswa dilatih untuk mengetahui Peranan Pembelajaran Cooperative Learning dalam belajar dan menumbuhkan kreasi dalam pembelajaran. Langkah awal mengetahui peranan Pembelajaran Cooperative Learning adalah: (1) menemukan halhal yang dapat dijadikan penguat belajar; (2) memperjelas tujuan belajar yang hendak dicapai; (3) menentukan ragam kembali terhadap rangsangan belajar; (4) menentukan ketekunan belajar. Dalam hal ini seseorang siswa yang belajar dihadapkan pada suatu masalah yang memerlukan pemecahan, dan hanya dapat dipecahkan berkat bantuan hal-hal yang pernah dilaluinya(Sudestia Ningsih, 2016). Siswa akan tertarik untuk belajar sesuatu, jika yang dipelajari itu sedikitnya sudah dapat diketahui atau dinikmati manfaat bagi siswa dan peranan kemampuan berpikir kreatif terakhir 
adalah berusaha mempelajari dengan baik dan tekun, dengan harapan memperoleh hasil yang baik. Langkah berikutnya adalah memberi pelatihan menumbuhkan Pembelajaran Cooperative Learning dapat juga dikaitkan dengan proses belajar mengajar di sekolah hal ini turut mempengaruhi dorongan rasa keinginan tahun siswa guna merespon segala permasalahan yang timbul di sekolah(Dale, 2012). Hal yang terpenting untuk menumbuhkan rasa motivasi siswa adalah peran aktif guru untuk membangkitkan semangat siswa sehingga diharapkan terjadi hal-hal yang positif terjadi. Siswa yang kreatif sering menjadi inspirasi siswa yang lain sehingga menambah pengalaman siswa karena apa yang diperhatikan tentu membangkitkan Pembelajaran Cooperative Learning sejauh apa yang dilihat itu mempunyai hubungan dengan kepentingan dirinya sendiri sehingga menimbulkan tindakan secara langsung. Kegiatan memberikan Pembelajaran Cooperative Learning melibatkan semua siswa dalam satu kelas. Instruktur menceritakan berbagai orang yang menginspirasi dan melibatkan siswa selama proses pembelajaran dengan memberi kesimpulan makna dibalik cerita yang menginspirasi. Kegiatan ini dilakukan di kelompok kecil beranggotakan siswa dengan anggota beberapa siswa. Di awal program, instruktur mengidentifikasi siswa yang kurang Pembelajaran Cooperative Learning kemudian mengelompokkannya. Instruktur memilih dan memperkenalkan sesuatu yang menginspirasi serta membimbing setiap siswa dalam memaknai dan memahami hal yang menginspirasi. Bimbingan diberikan selama kegiatan berlangsung baik sebelum, saat, dan setelah memberi hal yang menginspirasi, awal pelaksanaan pelatihan penerapan kemampuan berpikir kreatif, guru disarankan menggunakan semua kelompok selama satu semester(Demitra, 2012). Hal ini dimaksudkan untuk membantu guru mengenali dan memahami proses pelaksanaan kegiatan tersebut.

Pembelajaran dengan Cooperative Learning merupakan suatu pembelajaran kelompok dengan jumlah peserta didik 2-5 orang dengan gagasan untuk saling memotivasi antara anggotanya untuk saling membantu agar tercapainya suatu tujuan pembelajaran yang maksimal(Rizka Dhini Kurnia, 2014). Ciri-ciri pembelajaran dengan konsep Cooperative Learning adalah: (a) untuk menuntaskan materi belajar, siswa belajar dalam kelompok secara bekerja sama; (b) kelompok dibentuk dari siswa yang memiliki kemampuan tinggi, sedang dan rendah; (c) jika dalam kelas terdapat siswa- siswa yang heterogen ras, suku, budaya, dan jenis kelamin, maka diupayakan agar tiap kelompok terdapat keheterogenan tersebut; (d) penghargaan lebih diutamakan pada kerja kelompok daripada perorangan. Tujuan dengan pembelajaran model Cooperative Learning adalah: (a) dapat meningkatkan hasil belajar akademik; (b) penerimaan terhadap keragaman, yaitu agar siswa menerima teman-temannya yang mempunyai berbagai latar belakang; (c) pengembangan keterampilan sosial, yaitu untuk mengembangkan keterampilan sosial siswa diantaranya: berbagi tugas, aktif bertanya, menghargai pendapat orang lain, memotivasi teman untuk bertanya, mau mengungkapkan ide, dan bekerja dalam kelompok. Manfaat pembelajaran dengan model Cooperative Learning adalah(Syaodih \& Langlangbuana, 2011): (a) siswa yang diajari dengan dan dalam strukturtruktur kooperatif akan memperoleh hasil pembelajaran yang lebih tinggi; (b) siswa yang berpartisipasi dalam pembelajaran kooperatif akan memiliki sikap harga diri yang lebih tinggi dan motivasi yang lebih besar untuk belajar; (c) dengan pembelajaran kooperatif, siswa menjadi lebih peduli pada teman-temannya, dan diantara mereka akan terbangun rasa ketergantungan yang positif untuk proses belajar; (d) pembelajaran kooperatif meningkatkan rasa penerimaan siswa terhadap teman-temannya yang berasal dari latar belakang ras dan etnik yang berbeda.

Pelaksanaan model pembelajaran dengan model Cooperative Learning dilaksanakan sesuai dengan jadwal kegiatan pembelajaran matematika. pelaksanaan model Cooperative Learning dilakukan pada pertemuan ke-2 sampai dengan pertemuan ke-4. Pada pertemuan ke-2 ini siswa sudah dibagi perkelompok dan diberi proyek untuk diselesaikan secara berkelompok. Setiap minggu dimulai dari minggu ke-2 masing-masing kelompok melaporan kemajuan kerja kelompok dengan presentasi didepan kelas. Sedangkan kelompok lain memperhatikan hasil kerja kelompok yang sedang presentasi dan melakukan diskusi sekitar tentang tugas kelompok. Dengan pelaksanaan model seperti, menurut diskusi dengan para siswa, model seperti ini sangat menarik sekali. karena masingmasing individu dapat berkreasi, saling diskusi dengan sesama tim dan proses pembelajaran akan semakin interaktif.(Sudestia Ningsih, 2016)

Secara detail pelaksanaan model pembelajaran adalah: (a) mulai dari perencanaan yaitu penyiapan administrasi seperti data siswa, silabus dan RPP; (b) penetapan kelompok siswa; (c) Perencaan bobot nilai; (d) menyususn instrumen tindakan (lembar observasi, tes hasil belajar, angket tentang respon siswa terhadap tindakan yang diberikan). Pelaksanaan model pembelajaran ini dilakukan secara berkelanjutan dan setiap pertemuan selalu diadakan evaluasi hasil kegiatan kerja kelompok.(Siti Aisyah, Adelina Hasyim, 2014) Hal ini dapat dilihat dari hasil yang telah dicapai oleh masing-masing kelompok. Dengan cara model ini, dari hasil diskusi dengan siswa, didapat hasil bahwa belajar matematika ternyata tidaklah sulit seperti yang mereka bayangkan. Hal ini bukti bahwa 
mereka sudah dapat menguasai dan menerapkan ilmu yang didapat.

Input : Pemberdayakan Kompetensi Guru Dalam Penguatan Model Pembelajaran Cooperative Learning Siswa di SDN Kenari 07 Pagi

Proses : Pemberdayakan Kompetensi Guru Dalam Penguatan Model Pembelajaran Cooperative Learning, menambah wawasan dan memahami perkembangan pendidikan serta mampu memanfaatkan informasi dalam sistem pendidikan dalam bentuk transfer ilmu dari berbagai
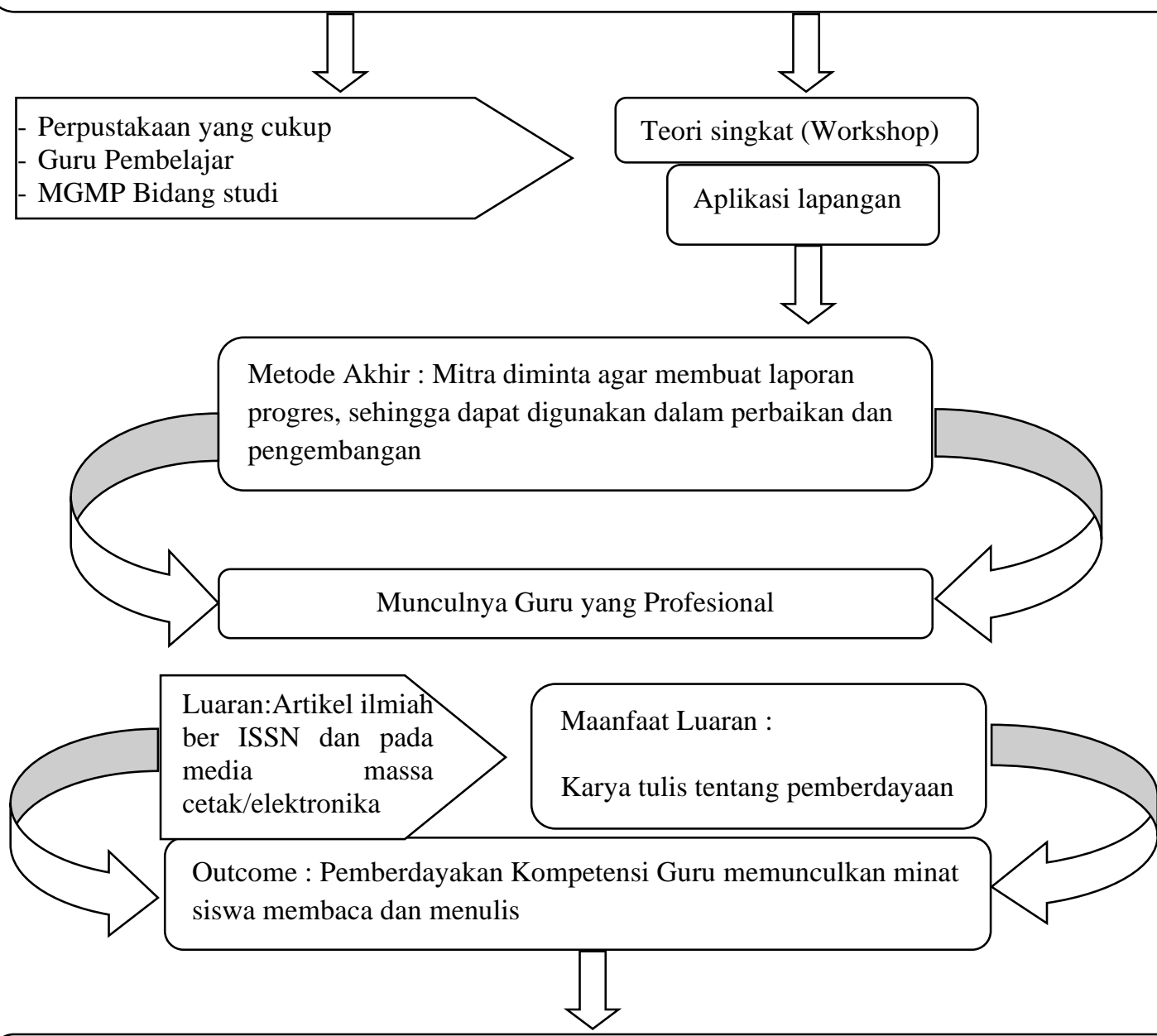

Evaluation : Perguruan Tinggi dapat memperoleh progres Pemberdayakan Kompetensi Guru Dalam Penguatan Model Pembelajaran Cooperative Learning yang diajarkan secara berkesinambungan

\section{HASIL DAN PEMBAHASAN}

Metode pendekatan untuk mendukung Pemberdayakan Kompetensi Guru Dalam Penguatan Model Pembelajaran Cooperative Learning di SDN Kenari 07 Pagi meliputi:
1) Pendekatan teori singkat (Workshop):

Dalam hal ini PT mengumpulkan pendidik untuk melakukan Pemberdayakan Kompetensi Guru Dalam Penguatan Model Pembelajaran Cooperative Learning sehingga memperoleh wawasan pendahuluan. 
2) Pendekatan aplikasi lapangan PT melakukan bimbingan dilapangan kepada seluruh mitra secara bertahap yang diwujudkan dari teori ke aplikasi.

3) Pendekatan evaluasi Dalam hal ini PT melakukan survey lapangan untuk memperoleh seberapa efektif pelatihan yang telah dilaksanakan.

Pendekatan ini untuk memperoleh gambaran terhadap kendala yang dihadapi mitra yang pada akhirnya para mitra diminta agar membuat laporan progres, sehingga dapat digunakan dalam perbaikan dan pengembangan.

Setelah menyusun rencana kegiatan selama 1 bulan dilanjutkan pemberian laporan setelah empat bulan selesai Pemberdayakan Kompetensi Guru Dalam Penguatan Model Pembelajaran Cooperative Learning. Dalam kegiatan ini diharapkan partisipasi mitra adalah sebagai berikut:

1. Mitra terdaftar sekurang-kurangnya 30 Peserta, dan yang mengikuti workshop diharapkan $100 \%$.

Dari kegiatan ini diharapkan mitra selalu berinteraksi dan mendiskusikan berbagai masalah yang dihadapi oleh setiap mitra, sehingga pelatih dapat memberikan solusinya melalui landasan teori.

2. Dalam bimbingan lapangan, diharapkan dapat dibimbing $100 \%$

Dalam bimbingan ini diharapkan mitra berpartisipasi dalam menyampaikan masalah, sehingga dapat diatasi secara langsung secara bertahap kepada masing-masing mitra.

Dengan bimbingan ini, mitra diharapkan memperoleh kemudahan mengerjakan dan menyelesaikan Pemberdayakan Kompetensi Guru Dalam Penguatan Model Pembelajaran Cooperative Learning.

3. Dalam kegiatan evaluasi, diharapkan PT dapat memperoleh progres Pemberdayakan Kompetensi Guru Dalam Penguatan Model Pembelajaran Cooperative Learning yang diajarkan pada peserta didik dan membuat laporan secara lengkap tentang progres dari berbagai kegiatan yang telah dilakukan. Dengan menerima laporan lengkap dari berbagai kegiatan yang dilakukan oleh pendidik, dapat disimpulkan bahwa berapa persen dapat berhasil dan berapa persen yang kurang berhasil.

\section{E. DAFTAR PUSTAKA}

Dale. (2012). Learning Theories an Education Perspective. Pustaka Pelajar.

Demitra, S. (2012). Pengembangan Model Pembelajaran Kooperatif Handep Untuk
Dari hasil analisis ini dapat diketahui teknis apa yang akan digunakan untuk memenuhi kebutuhan sendiri mitra. Manfaat yang akan dihasilkan adalah peserta didik dapat memahami Pemberdayakan Kompetensi Guru dengan cara yang efesien dan efektif. Teknologi yang digunakan cukup sederhana sehingga meminimalisasi biaya yaitu dengan mengunakan bahan yang ada di sekitar sebagai contoh dalam mengaplikasikan Pemberdayakan Kompetensi Guru.

\section{PENUTUP}

\section{Simpulan}

Kegiatan Pemberdayakan Kompetensi Guru Dalam Penguatan Model Pembelajaran Cooperative Learning di SDN Kenari 07 Pagi dapat berjalan dengan lancar. Semua peserta terlihat antusias dan merasakan manfaatnya. Keberhasilan ini ditunjukkan antara lain:

1. Dalam penyampaian materi oleh seorang guru juga akan sangat berpengaruh terhadap pembelajaran siswa yang diajar.

2. Kecerdasan seorang guru Sekolah Dasar dalam menyampaikan materi perlu didukung oleh peran orang tua murid.

3. Para orang tua murid perlu diberikan suatu tindakan yang berguna mempermudahkan siswa menambah informasi pelajaran yang sedang berlangsung.

4. Peserta didik diharapkan aktif bertanya pada saat mengalami kesulitan dalam menyelesaikan kebiasaan Gerakan Literasi Siswa.

\section{Saran}

Karena adanya peningkatan Pemberdayakan Kompetensi Guru Dalam Penguatan Model Pembelajaran Cooperative Learning yang signifikan dari penggunaan pengajaran ini maka disarankan kepada guru hendaknya lebih mempertimbangkan penggunaan pendekatan Kompetensi Guru, sebagai salah satu metode yang perlu dikembangkan dalam proses belajar mengajar.

\section{Pembelajaran Matematika. JURNAL PENDIDIKAN DAN PEMBELAJARAN, 19(1).}

Manurung. S. Alberth, halim. A, R. A. (2020). Pengaruh Kemampuan Berpikir Kreatif untuk meningkatkan Hasil Belajar Matematika di Sekolah Dasar. Jurnal Basicedu, 4(4), 1291- 
1301.

https://doi.org/https://doi.org/10.31004/basic edu.v4i4.544

Nurlaila, N. (2019). PENGEMBANGAN MODEL COOPERATIVE LEARNING UNTUK PENDIDIKAN TINGGI. LENTERA PENDIDIKAN, 22(2), 213-222.

Randeska Manullang, M. F. R. (2017). PENGEMBANGAN MODEL PEMBELAJARAN BERBASIS KOOPERATIF. JURNAL NIAGAWAN, 6(2).

Rizka Dhini Kurnia, E. L. (2014). Pengembangan Model Pembelajaran Berbasis Cooperative Learning dalam Meningkatkan Motivasi Belajar Mahasiswa. Jurnal Sistem Informasi (JSI), 6(1).

Siti Aisyah, Adelina Hasyim, R. R. (2014). PENGEMBANGAN MODEL PEMBELAJARAN KOOPERATIF LEARNING TIPE MAKE A MATCH Jurnal Teknologi Informasi Komunikasi Pendidikan Vol 2, No 3 (2014) Riswandi. Jurnal Teknologi Informasi Komunikasi Pendidikan, 2(3).

Slameto. (2010). Belajar \& Faktor-Faktor yang mempengaruhi. Rineka Cipta.
Sudestia Ningsih, N. K. (2016). PENERAPAN METODE COOPERATIVE LEARNING UNTUK MENINGKATKAN KEMAMPUAN KOGNITIF. Ilmiah Potensia, 1(2), 100-106.

Syaodih, E., \& Langlangbuana, U. (2011). Pengembangan Model Pembelajaran Kooperatif Utnuk. 1.

Wanelly, W., \& Fauzan, A. (2020). Pengaruh Pendekatan Open Ended dan Gaya Belajar Siswa terhadap Kemampuan Berpikir Kreatif Matematis. Jurnal Basicedu, 4(3), 523-533. https://doi.org/10.31004/basicedu.v4i3.388

Weeks, D. P. C. C. L. E. Y. N. to K. in 20. (2015). Penerapan model cooperative learning dalam meningkatkan hasil belajar. $D k, 53(9), 1689-$ 1699.

Zerri Rahman Hakim, Taufik,M.Pd, Q. A. (2018). PENERAPAN MODEL PEMBELAJARAN COOPERATIVE LEARNING TIPE TALKING STICK TERHADAP PEMAHAMAN. Pesona Dasar, 6(2), 75-84. 